\title{
A Framework to Integrate Databases with Building Information Modelling for Building Energy Assessment
}

\author{
Danny Lobos ${ }^{1}$, Eric Henríquez Jara ${ }^{2}$, David Blanco ${ }^{1}$, Pablo Pulgar ${ }^{1}$ \\ ${ }^{1}$ Universidad Tecnológica Metropolitana, Santiago, Chile. \\ ${ }^{2}$ Universidad del Bio-bio, Concepcion, Chile
}

\begin{abstract}
BIM models are seldom used for energy certification of buildings. This paper discusses the advantages of linking two important fields; Building Information Modelling (BIM) and Building Environmental Assessment Methods (BEAM), better known as a rating system. The state-ofthe-art in both fields around the world is discussed, with an in-depth examination of current BIM software and related applications, followed by a discussion about previous research for integrating them. Finally, a new framework is proposed based on database exchange that takes crucial information from BIM to BEAM platforms. The development of this method includes BIM programming, database links, and spreadsheets for building energy certification. This new semi-automatic tool allows architects to model their design in the BIM platform and use this information as an input for the energy certification process. The potential and risks of this method are discussed.
\end{abstract}

\section{Introduction}

Building Environmental Assessment Methods, or BEAM (Burnett \& Yik, 2001; IGBC., 2013), such as LEED (US), BREEAM (UK), DGNB (Germany), and CES (Chile) are used to certify various energy aspects. All of them require a large amount of complex building data to complete all required documents and forms. On the other hand, Building Information Modelling (BIM) technologies support the whole building lifecycle and have plenty of rich geometry and data that has great potential to provide strong support of the energy analysis and assessment of buildings, even more so for design teams in early stages. This research addresses the automated exchange of information between these three environments. In recent years, as the need for sustainable building has increased rapidly, various factors, such as energy costs, the effect of $\mathrm{CO} 2$ on the planet, public and government trends, and new technology becoming available, have led to a requirement for better building performance. Several versions of BPS (Building Performance Simulation) software have been used to simulate energy demands, lighting, heat gains, $\mathrm{CO} 2$ emissions, etc.

\section{Overview in BIM technologies}

Several definitions have been established for the term BIM and also for its usability in the AEC industry. Mass adoption of BIM began in 2000, and in 2003 government implementation began as a standard for public buildings such as the 3D-4D BIM Program at the GSA (GSA, 2016), Government Construction Strategy in UK (Government Construction Strategy UK., 2016), and Staatsbyg in Finland. Early stages of design are also fully supported (D Lobos, 2011). BIM technologies are the current paradigm in practice for building and infrastructure (Eastman, Teicholz, Sacks, \& Liston, 2011; Jones, 2014; NBS., 2016).

Many of the current commercial BIM software packages include an energy analysis tool. For example, Autodesk Revit has the Light Analysis plug-in and also the Insight 360 plug-in (see Figure 1) that runs analysis for illuminance and validation of LEED v3 IEQc8.1 and LEED v4 IEQ Daylight Credit-Option 2 (Stine, 2015). Graphisoft provides EcoDesigner Star for ASHRAE 140-2007 and ASHRAE 90.1-2007 (LEED Energy) analysis. Meanwhile, the Bentley AECOsim Energy Simulator tool runs simulations that generate documentation and reports, which are compliant with ASHRAE Standard 90.1 and LEED certified (Bentley Institute., 2016), and finally Allplan Nemetscheck provides software templates to obtain LEED SS Credit 5.1 during conceptual design (Ich BiM., 2014). We can conclude that BIM vendors have become concerned about integration with LEED, with most of them proposing to work within their BIM environment, but ultimately there is no strong evidence of test cases or real projects, or its use among energy consultants.

\section{BPS software in brief}

DesignBuilder, TAS, Daysim, Green Building Studio, and IES_VE, are the most well-known software packages, among others, (see Figure 2) (Attia, Hensen, Beltrán, \& De Herde, 2012; BEST Directory., 2016; Clarke \& Hensen, 2015; Crawley, Hand, Michaël, \& Griffith, 2005; Raslan \& Davies, 2010). These types of software have demonstrated their usefulness in simulating building performance aspects (CO2 emissions, LEED credit analysis-lighting, thermal loads, solar, acoustic, etc.) with higher precision and speed. Nevertheless, their usability requires extensive training and 
documents. Although BIM-BPS exchange has been proposed by many authors (Bazjanac \& Maile, 2004; Calquin, Wandersleben, \& Castillo, 2014; PradaHernandez, Rojas-Quintero, Vallejo-Borda, \& PonzTienda, 2015), there is no strong evidence of their mixed use in practice.

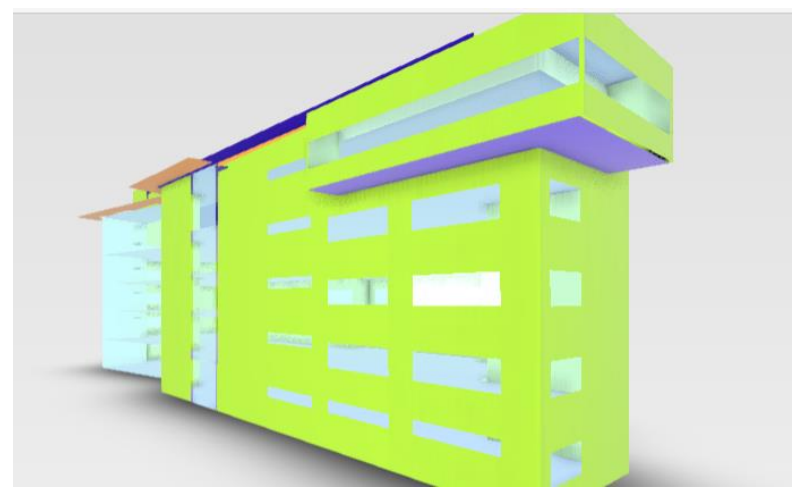

Figure 1: Insight 360 Model for Police Headquarters in the South of Chile. Source: Silva (2017).

\section{Building Energy Assessments Methods for buildings}

The Building Energy Assessments Methods (BEAM) are normally based on credits for each criterion and recognise different types of buildings, stages, and certification categories. However, not all of them are strongly connected to BIM or BPS software, since many data must be manually updated from any simulation or 3D model. Usually, all efforts made in making BIM models are wasted when energy consultants start assessing the building to obtain BEAM certification (LEED, Breeam, DGNB). Rating systems such as LEED (US), BREEAM (UK), DGNB (Germany), and CES (Chile), and many others have stimulated the real estate market and government by providing more confidence in the sustainability of a building (Ramírez-Villegas, Eriksson, \& Olofsson, 2016; Seinre, Kurnitski, \& Voll, 2014; P. Wu, Mao, Wang, Song, \& Wang, 2016).

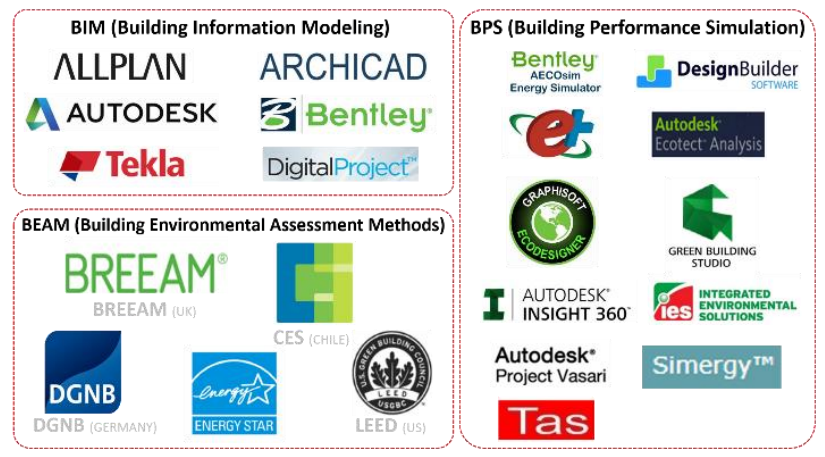

Figure 2: An overview of BIM software, BPS software, and BEAM schemes. Prepared by the authors, 2018.

\section{Missing Links between BIM, BPS and BEAM}

There are some missing links between BIM, BPS, and BEAM. Many operations, such as the interoperability of BIM and BPS, the challenges in the collaborative integrated design process, the lack of model and interface standards, and the requirements of building performance apsessementogndf qRBGern Ital prgetitionerssand researchers (Azhar, Carlton, shared successfully within the BEAM environment or vice versa. One of the first BIM and energy integration efforts (Schlueter \& Thesseling, 2009) did not include any BEAM rating system. Some recent efforts include integrating BIM and LEED systems at the conceptual design stage (Jalaei \& Jrade, 2015). Nevertheless, all information required in BEAM documents must still be completed manually (CES Instituto de la Construcción., 2016; USGBC., 2016) and new information must be updated manually after design changes (Kryegel \& Nies, 2008) such as adding or deleting stories/areas/rooms, resizing/rotating rooms, moving walls, changing materials, etc. Providing required/achieved performance information to design teams is also a failing of most the BIM software packages.

\section{Research on BIM-BPS-BEAM integration}

Recent research concerning the integration of BIM, BPS, and BEAM. Al-Ghamdi, Bilec, 2017 carried out a comparative study using three LCA software tools, where adding another BIM MEP systems finally gets more holistic Life Cycle Assessment. Marzouka, Abdelkaderb, Al-Gahtanica (2017) developed a global tool for existing buildings with BIM, showed that weights in certification vary from country to another, however, energy criteria have nearly the same weight. Kwok-WaiWong, Ka-Lin Kuan (2014) explore the potential of BIM used for BEAM Plus certification rating system, the study indicated that 26 out of 80 credit points could potentially be achieved with BIM (i.e. Autodesk Revit). Röcka, Hollbergb, Habertb, Passera (2018) proposed an BIM-integrated approach, where the building model of early stages was used for LCA. Yang, Hu, Wu (2018) presents a BIM-enabled LCA method and illustrates how the method can be used to facilitate the low carbon design for the AEC sector. Marzouk, Abdelkader, Gahtani (2017) presents a building information modeling (BIM)-based model that enables the estimation of six types of emissions for the overall project life cycle phases.

Recent market research reports reveal the great potential of integration for the industry (Jones, 2014). (Bazjanac, 2008) was one the first authors dealing with BIM-IFC exchange to improve energy design for buildings. There have been also some recent efforts concerning the integration of these three fields, such as integrating BIM and the LEED system at the conceptual design stage (Jalaei \& Jrade, 2015), but depending on a commercial BIM package (Autodesk Revit); using cloud-BIM for LEED automation (W. Wu \& Issa, 2013); BIM execution planning in Green Building projects (Wei $\mathrm{Wu} \&$ Issa, 2015); certain guidelines for using BIM for energy analysis of buildings (Reeves, Olbina, \& Issa, 2015); and integrated process mapping for BIM implementation in Green Building project delivery (W. Wu \& Issa, 2013). (Remmen et al., 2015) promotes an open framework for integrated BIM-based Building Performance Simulation using Modelica. In the early 2000s Bayforrest dealt with connecting an IFC-compliant product model of a building (using Autodesk Architectural Desktop, a proto BIM software) via the internet with databases for the resource and energy requirements of building materials (Neuberg, Fank, \& Ekkerlein, 2004) not connected to any BEAM scheme. The use of BIM-based Model Checking (BMC) was proposed for DGNB Dalifish 
version (Gade, Svidt, \& Jensen, 2016). In conclusion, there are only a few methods to fill out BEAM forms directly using BIM software in order to speed up and make the certification process of a building more accurate but are not available for testing. In addition, there is a lack of an intuitive interface to carry out this exchange.

\section{A New Framework for Integration}

This research proposes a novel framework (see Figure 3), including information exchange between BIM and BEAM.
In this framework we begin by recognising BEAM requirements (i.e. LEED, Breeam, DGNB, Chilean CES) and then we model the BIM for architectural design (under BPS protocols). It is then evaluated in a BPS environment (i.e. DesignBuilder, TAS, EcoDesigner, Green Building Studio) and if changes are required, they are made in the BIM model and then the BEAM requirements are met.

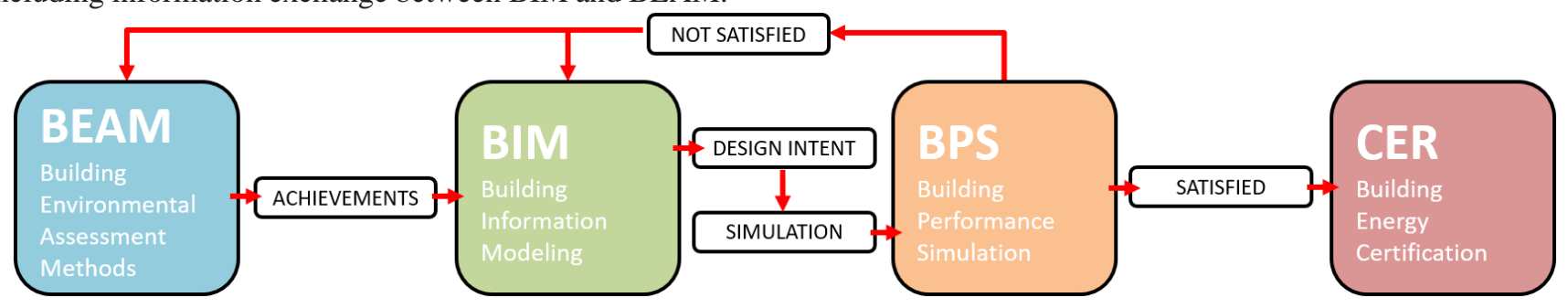

Figure 3: Proposed new framework. Source: Prepared by the authors (2018).

Table 1: CES criteria that can be filled out from the BIM tool. Prepared by the authors, 2018.

\begin{tabular}{lll}
\hline $\begin{array}{l}\text { BIM } \\
\text { potential }\end{array}$ & Item & Variable \\
\hline Full & General information & Location, Owner, Project name, Customer ID, Area. \\
\hline Full & Use and location & City location, Days of use /week. \\
\hline Full & Definitions rooms & $\begin{array}{l}\text { Numbering of enclosures, Room name, Description, Useful area, Density of } \\
\text { usage, Lighting charge, Equipment loads, regularly occupied. }\end{array}$ \\
\hline Full & Definition of groups & Group numbering, Group name. \\
\hline Full & $\begin{array}{l}\text { Allocation of Enclosures to } \\
\text { different groups }\end{array}$ & Numbering of rooms, Room name, Group to which it belongs. \\
\hline Full & Surrounding & $\begin{array}{l}\text { Area, Height, Material (Walls / Ceilings / Floor), Thickness (Walls / Ceilings / } \\
\text { Floor), Insulation (Walls / Ceilings / Flooring). }\end{array}$ \\
\hline Partial & Infiltration and air changes & Infiltration and air renewal, Night ventilation. \\
\hline Full/Partial & Radiation & Orientation, Dimension, Visible light transmittance, Solar factor glass. \\
\hline Full & $\begin{array}{l}\text { Features of window frames in } \\
\text { each orientation }\end{array}$ & Facade obstacle dimensions. \\
\hline Full & Ventilation & Room area, Height, Use, Occupational density. \\
\hline
\end{tabular}

An automated information exchange method between a BIM platform (Autodesk Revit) and Chilean certification (called CES) was developed as a case for this framework and is discussed below. The proposed framework was based on knowledge of both topics (BIM and BEAM), which are normally separate and depend on different practitioners. The method was to map both processes (BIM/BEAM). Here, a strong BIM potential and match was found between several variables (See Table 1). Then a database connection (MS Access) between proprietary BIM software (Autodesk Revit 2017) and a BEAM spreadsheet format (part of the Chilean CES rating system) was set up, allowing automated completion and update from the BIM model created by architects.

\section{First results from tests}

A novel flow of information from BIM to BEAM was used for both tests. Once the initial set up is completed (names,

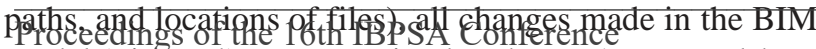
model (Figurest) are transmigted to the BEAM spreadsheet through the database link (Figure 5). This means that after every design change (floor, rooms, sizes, and names) made in the BIM model, all of the required information is automatically transmitted to the BEAM spreadsheet (Danny Lobos, 2017). A list of the criteria taken from BIM to Chilean BEAM (called CES) can be found in Table 1.

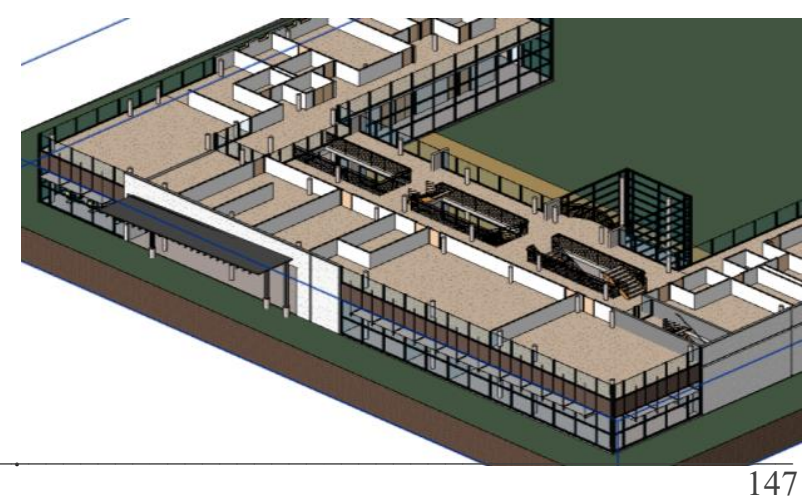




\begin{tabular}{|c|c|c|c|c|c|c|c|}
\hline \multicolumn{8}{|c|}{ All Access Obje... $\odot \ll$} \\
\hline \multirow{2}{*}{$\begin{array}{l}\text { Search } \\
\# \\
\text { 困 }\end{array}$} & \multirow{2}{*}{$\begin{array}{l}\text { RoomAssociations } \\
\text { RoomFromToAssociations }\end{array}$} & \multirow[t]{2}{*}{$\begin{array}{l}\rho \\
\end{array}$} & \multicolumn{5}{|l|}{ 团 } \\
\hline & & & & Área & 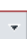 & Número & - Nombre \\
\hline 团 & Rooms & & 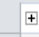 & 40,79664 & & 101 & Vest. \\
\hline 困 & RoomTags & & $\oplus$ & 327,1892 & & 102 & Lobby \\
\hline & & & Ф & 146,9605 & & 121 & Cafeteria \\
\hline 田 & SecurityDevices & & + & 22,2086 & & 122 & Prep/Dish \\
\hline 团 & SecurityDeviceTypes & & 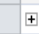 & 8,4627 & & 124 & Dry Storage \\
\hline 团 & ServiceTypeEnums & & $\oplus$ & 5,690335 & & 125 & Electrical \\
\hline 团 & Sheets & & 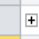 & 41,50160 & 915 & 123 & Conference \\
\hline 目 & Site & & + & 15,35942 & 811 & 127 & Office \\
\hline & & & + & 15,70892 & 540 & 126 & Admin \\
\hline 田 & SiteTypes & & $\oplus$ & 9,70028 & & 128 & Storage \\
\hline 团 & SlabEdges & & 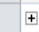 & 5,575666 & 633 & 129 & Toilet \\
\hline 团 & SlabEdgeTypes & & 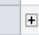 & 18,9 & & 130 & Stair \\
\hline 团 & SpaceAssociations & & ఉ & 54,62438 & & 131 & Corridor \\
\hline 团 & Spaces & & $\oplus$ & 8,900521 & 125 & 119 & Sprinkler \\
\hline
\end{tabular}

Figure 5: Screenshot from database (Microsoft Access) used to connect BIM Model information to be transferred to BEAM spreadsheet. Source: Prepared by the authors, 2016.

The information from the BIM model is extracted to an external database, filtered, tabulated, and translated into the CES (Chilean rating system) spreadsheet form. This allows huge amounts of information to be shared from BIM to BEAM and adds more speed and accuracy to the process of building an energy assessment.

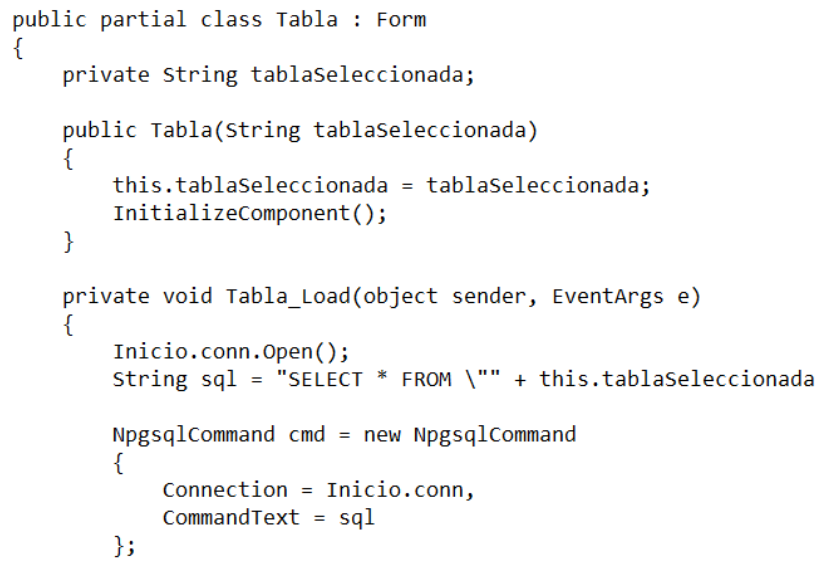

Figure 6: A new tool coded in C\#, it connects the BIM Database with the CES spreadsheets. Source: Prepared by the authors, 2018.

\section{BIM tool prototype}

There was a prototypical version consisting of the development of a new tool within commercial BIM software. The tool was coded in C\# and it connects the BIM Database contained in Revit with the CES spreadsheets. It extracts information from the BIM model and automatically fills in the BEAM spreadsheet (see Figure 6). This allows the framework to work independently from any commercial plug-in or software, and it also allows future

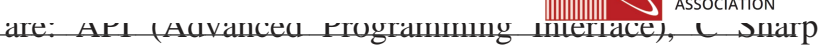
programming language, Autodesk Revit 2017 and PostgreSQL (open source database). Algorithm details are described (see Figure 8). Architects shows their design efforts through BIM models, their design follows BEAM requirements (LEED, BREAM, CES), and the new tool (step1) extracts all information from the BIM model (classes: Walls, Windows, Slabs, Stairs, Ceiling, Level) to an external database (PostgreSQL in step2). From this database a filter is applied to extract information and then only useful information is selected and taken to the BEAM local database (Chilean CES in this case). Finally, a single user can automatically have this information in any spreadsheet (such as Microsoft Excel) to create fast and accurate reports about the performance of the building in respect to a BEAM scheme.

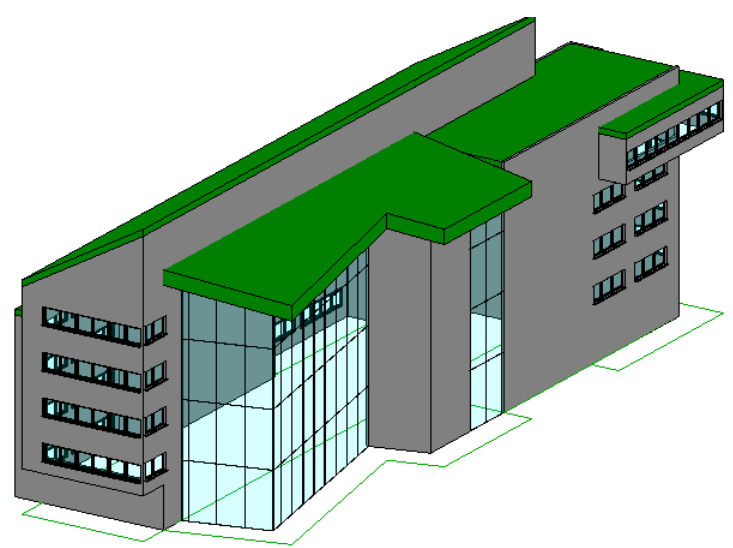

Figure 7 A PDI (Policía de Investigaciones) building located in the South of Chile. Source: Prepared by the authors, 2018.

\section{Case Study}

Next a theoretical case study is proposed. A PDI (Policía de Investigaciones) building located in the South of Chile is presented. It is a $4.182 \mathrm{~m} 2$ distributed in five floors and one underground level (Concrete and Crystal Façade). The building was already approved by Chilean CES certification. All requirements shown in Table 1 were automatically extracted from the BIM model of the building and taken into the CES spreadsheets. After fulfilling manually other aspects of the building (information that is not coming from a BIM model) the CES engine was run and the results was a $133 \mathrm{kWh} / \mathrm{m} 2 / \mathrm{yr}$ that was clearly in the range accepted by the Chilean CES method. 


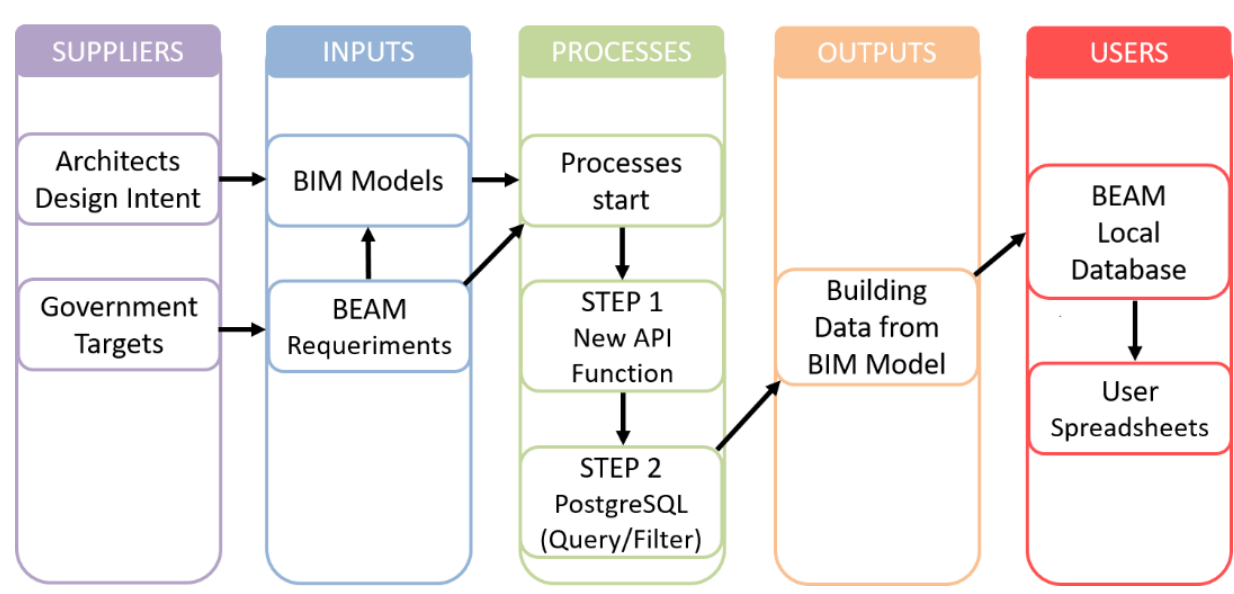

Figure 8: Information flow process. Source: Prepared by the authors, 2018.

\section{Discussion}

This new workflow has several advantages. At present, most BEAM documents must be completed manually. BIM models collect a great deal of useful information for BEAM documents and only a few articles deal with this problem and they address it only partially. The proposed workflow creates a new automated connection between BIM information and BEAM documents. Providing required/achieved performance information to design teams is also a significant contribution of this work. This case shows the use of the proposed framework in a specific workflow (Revit-CES), which could be applied to ArchiCAD-LEED, Bentley-BREEAM, or any other local BEAM scheme or any new BPS/BIM software.

Some difficulties can be faced when trying to repeat this method in a real context: the lack of special BIM models for CES Method, the lack of interoperability with all BIM vendors (Autodesk, Graphisoft, Bentley, etc), the lack of knowledge about BIM models advantages from the Energy Consultants. Some other challenges for the right implementation of this concept are issues related to the building database (missing data, new database system, BIM software).

\section{Conclusions}

The results of this research show that a large amount of useful information added to BIM models can be reused in BEAM schemes. Currently there is no real full integration between the BIM-BPS-BEAM fields that is useful for architectural practice. Government BIM mandates do not normally include clear BEAM specifications or any application to link them. An exception is the GSA 3D-4D BIM Program, which includes clear guidelines to support building energy modelling and simulation from BIM Models. BIM mandates and BEAM schemes should work together more clearly. Regional assessment schemes such as Chilean CES are not applicable in other regions, but the exchange method via database exchange is valid for other schemes (LEED, Breeam, DGNB, etc.) or BIM/BPS software.

\section{Outlook}

For future work, there are some extended aspects that should be addressed, such as: case studies, web integration, complianee with government building energy polieies, Proceedings of the 16 th IBPSA Conference for
ease of use, a more comprehensive interface for other BIM Rome, Italy, Sept. 2-4, 2019 software (ArchiCAD, Bentley, Allplan, Digital Project), exchange of information from/to BPS (Design Builder, IES_VE, TAS) may be addressed, IFC compliance for promoting OpenBIM standards, and more direct linkage to Energy+ engine.

\section{Acknowledgements}

This research was fully supported by Fondecyt Iniciación 11151024 Grant, and partially supported by Magister BIM and Magister en Eficiencia Energetica y Sustentabilidad postgraduate programs, and EFICONS Research Center at UTEM.

\section{References}

Attia, S., Hensen, J. L. M., Beltrán, L., \& De Herde, A. (2012). Selection criteria for building performance simulation tools: contrasting architects' and engineers' needs. Journal of Building Performance Simulation, 5(3), $155-169$. https://doi.org/10.1080/19401493.2010.549573

Azhar, S., Carlton, W. A., Olsen, D., \& Ahmad, I. (2011). Building information modeling for sustainable design and LEED® rating analysis. Automation in Construction, 20(2), 217-224. https://doi.org/10.1016/j.autcon.2010.09.019

Bazjanac, V. (2008). IFC BIM-Based Methodology for Semi-Automated Building Energy Performance Simulation. In CIB-W78 25th Conference, July 15-17. Santiago, Chile.

Bazjanac, V., \& Maile, T. (2004). IFC HVAC interface to EnergyPlus - A case of expanded interoperability for energy simulation. In SimBuild 2004 (pp. 1-7). Boulder, CO, US.

Bentley Institute. (2016). AECOsim Energy Simulator V8i Fundamentals (imperial). Retrieved March 1, 2018, from https://www.bentley.com/en/products/productline/building-design-software/aecosim-energysimulator

BEST Directory. (2016). Building Energy Software Tools. Retrieved December 15, 2016, from http://www.buildingenergysoftwaretools.com

Burnett, J., \& Yik, F. W. (2001). Framework of Building Environmental Assessment Methods. HKIE Transactions, 8(3), 1-7.

Calquin, D. A. L., Wandersleben, G., \& Castille, L. S. (2014). Interoperability Map between BIM and BPS 
CES Instituto de la Construcción. (2016). Certificación Edificio Sustentable. Retrieved December 15, 2016, from http://certificacionsustentable.cl/

Clarke, J. A., \& Hensen, J. L. M. (2015). Integrated building performance simulation: Progress, prospects and requirements. Building and Environment, 91, 294306. https://doi.org/10.1016/j.buildenv.2015.04.002

Crawley, D. B., Hand, J. W., Michaël, K., \& Griffith, B. T. (2005). Contrasting the Capabilities of Building Energy Performance Simulation Programs. In Ninth International IBPSA Conference (pp. 231-238). Montréal, Canada.

Eastman, C., Teicholz, P., Sacks, R., \& Liston, K. (2011). BIM handbook: a guide to building information modeling for owners, managers, designers, engineers, and contractors (2nd ed.). New York: John Wiley.

Gade, P., Svidt, K., \& Jensen, R. (2016). Analysis of DGNB-DK criteria for BIM-based Model Checking automatization. Retrieved March 1, 2018, from http://vbn.aau.dk/da/publications/analysis-of-dgnbdkcriteria-for-bimbased-model-checkingautomatization\%28df19474a-0594-43ad-b41f$5785 \mathrm{~d} 2155 \mathrm{da} 8 \% 29 . \mathrm{html}$

Government Construction Strategy UK. (2016). Government Construction Strategy: 2016-2020. Retrieved March 1, 2018, from https://www.gov.uk/government/publications/govern ment-construction-strategy-2016-2020

GSA. (2016). GSA 3D-4D BIM Program. Retrieved March 1, 2018, from https://www.gsa.gov/portal/category/21062

Ich BiM. (2014). Ich BiM to Leed to Allplan. Retrieved March 1, 2018, from https://www.youtube.com/watch?v=fe7Tplh4V40

IGBC. (2013). Building Environmental Assessment Method for Ireland. Retrieved March 1, 2018, from https://www.igbc.ie/wpcontent/uploads/2014/11/IGBC-Guide-NEW-03-1013-2.pdf.

Jalaei, F., \& Jrade, A. (2015). Integrating building information modeling (BIM) and LEED system at the conceptual design stage of sustainable buildings. Sustainable Cities and Society, 18, 95-107. https://doi.org/10.1016/j.scs.2015.06.007

Jones, S. (2014). Recent SmartMarket BIM Research by McGraw Hill Construction.

Kryegel, E., \& Nies, B. (2008). Green BIM. Indianapolis: Wiley.

Lobos, D. (2011). BIM Supported Building Envelopes and Space Layout Based on a Case Study in South America (1st Edition). Weimar: Bauhaus Verlag.

Lobos, D. (2017). Automated Building Data Exchange between BIM and BPS Supporting Building Environmental Assessment Methods (BEAM). In Proceedings of the 15th IBPSA Conference (pp. 16671671). https://doi.org/10.26868/25222708.2017.339

Motawa, I., \& Carter, K. (2013). Sustainable BIM-based Evaluation of Buildings. Procedia - Social and Behavioral Sciences, 74, 419-428.

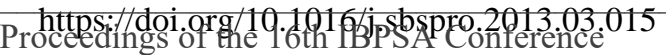

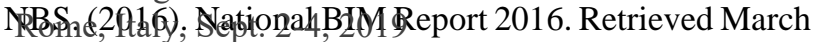

Neuberg, F., Fank, E., \& Ekkerlein, C. (2004). Integrated Life Cycle Simulation and Assessment of Buildings. In International Conference on Computing in Civil and Building Engineering, ICCCBE. Weimar, Germany.

Prada-Hernandez, A., Rojas-Quintero, J. S., VallejoBorda, J., \& Ponz-Tienda, J. L. (2015). Interoperability of Building Energy Modeling (BEM) with Building Information Modeling (BIM). In SIBRAGEC ELAGEC 2015. San Carlos, Brasil.

Ramírez-Villegas, R., Eriksson, O., \& Olofsson, T. (2016). Assessment of renovation measures for a dwelling area - Impacts on energy efficiency and building certification. Building and Environment, 97, 26-33. https://doi.org/10.1016/j.buildenv.2015.12.012

Raslan, R., \& Davies, M. (2010). Results variability in accredited building energy performance compliance demonstration software in the UK: an inter-model comparative study. Journal of Building Performance Simulation, 3(1), 63-85. https://doi.org/10.1080/19401490903477386

Reeves, T., Olbina, S., \& Issa, R. (2015). Guidelines for Using Building Information Modeling for Energy Analysis of Buildings. Buildings, 5(4), 1361-1388. https://doi.org/10.3390/buildings5041361

Remmen, P., Cao, J., Ebertshäuser, S., Frisch, J., Lauster, M., Maile, T., \& Wimmer, R. (2015). An open framework for integrated BIM-based building performance simulation using Modelica. In Proceedings of 14th IBPSA. Hyderabad, India.

Schlueter, A., \& Thesseling, F. (2009). Building information model based energy/exergy performance assessment in early design stages. Automation in Construction, 18(2), 153-163. https://doi.org/10.1016/j.autcon.2008.07.003

Seinre, E., Kurnitski, J., \& Voll, H. (2014). Building sustainability objective assessment in Estonian context and a comparative evaluation with LEED and BREEAM. Building and Environment, 82, 110-120. https://doi.org/10.1016/j.buildenv.2014.08.005

Stine, D. (2015). Building Performance Analysis in Revit 2016 R2 with Autodesk Insight 360. Retrieved March 1, 2018, from http://blogs.autodesk.com/insight/buildingperformance-analysis-in-revit-2016-r2-with-autodeskinsight-360/

USGBC. (2016). Guide to LEED Certification Commercial. from http://www.usgbc.org/cert-guide

Wu, P., Mao, C., Wang, J., Song, Y., \& Wang, X. (2016). A decade review of the credits obtained by LEED v2.2 certified green building projects. Building and Environment, 102, 167-178. https://doi.org/10.1016/j.buildenv.2016.03.026

Wu, W., \& Issa, R. (2013). Integrated process mapping for BIM implementation in green building project delivery. In Proceedings of the 13th International Conference on Construction Applications of Virtual Reality. London, UK.

Wu, W., \& Issa, R. R. A. (2015). BIM Execution Planning in Green Building Projects: LEED as a Use Case. Journal of Management in Engineering, 31(1), A4014007. https://doi.org/10.1061/(ASCE)ME.19435479.0000314 